\title{
Long-Term Weather Elements Prediction in Jordan using Adaptive Neuro-Fuzzy Inference System (ANFIS) with GIS Techniques
}

\author{
Omar Suleiman Arabeyyat \\ Computer Engineering Department \\ Al-Balqa Applied University, BAU \\ Al-Salt, Jordan
}

\begin{abstract}
Weather elements are the most important parameters in metrological and hydrological studies especially in semi-arid regions, like Jordan. The Adaptive Neuro-Fuzzy Inference System (ANFIS) is used here to predict the minimum and maximum temperature of rainfall for the next 10 years using 30 years' time series data for the period from 1985 to 2015. Several models were used based on different membership functions, different methods of optimization, and different dataset ratios for training and testing. By combining a neural network with a fuzzy system, the hybrid intelligent system results in a hybrid Neuro-Fuzzy system which is an approach that is good enough to simulate and predict rainfall events from longterm metrological data. In this study, the correlation coefficient and the mean square error were used to test the performance of the used model. ANFIS has successfully been used here to predict the minimum and maximum temperature of rainfall for the coming next 10 years and the results show a good consistence pattern compared to previous studies. The results showed a decrease in the annual average rainfall amounts in the next 10 years. The minimum average annual temperature showed the disappearance of a certain predicted zone by ANFIS when compared to actual data for the period 1985-2015, and the same results behavior has been noticed for the average annual maximum.
\end{abstract}

Keywords-Rainfall prediction; hybrid intelligent system; Adaptive Neuro-Fuzzy Inference System (ANFIS); GIS; time series prediction; long-term weather forecasting; climate change

\section{INTRODUCTION}

Rainfall plays an enormous role in climate classification. As a result, the climate in any area is strongly influenced by rainfall [5]. It is found that the rate of warming varies from one region to another on the earth surface, and the precipitation shows either increasing or decreasing rates in various regions on the earth's surface. Several decades of warming and a variety of hydrologic and landscape responses have already occurred, and these changes are expected to accelerate during the 21 st Century unless the greenhouse-gas emissions are brought under control and are even reversed [12].

Climate change studies in Jordan show that the minimum temperature has increased twice the rate of the maximum temperature increase [10]. One of the essential steps in climate change studies is the analysis of trends in the available records of climatological data for the selected stations. Weather forecasting is the application of science and technology to predict the state of the atmosphere for a future time and a given location [13]. One of the main fields of weather forecasting is rainfall prediction, which is important for the food production plan, water resource management and all activity plans in nature. Rainfall forecasting is a non-linear forecasting process that varies according to area. It is strongly influenced by climate change. Another parameter which is considered an element of climate is the temperature, in its both average annual maximum temperatures and the average annual minimum temperature; both temperatures can also give a good indication about the behavior of the weather. In this study, both temperatures are also introduced in the simulation process for the predication as well as for the rainfall.

In Jordan, and according to the rainfall pattern, different zones or regions have been created and grouped into three major categories and as follows, with the highest rainfall (400$600 \mathrm{~mm} / \mathrm{yr}$ ) occurring in the northwest of the country in upper land areas. The lower mean annual rainfall of (250-350) mm occurs in central Jordan. Mainly, the region is far north of the Jordan Valley. The lowest rainfall (less than $170 \mathrm{~mm} / \mathrm{yr}$ ) occurs in the lower land regions of the east and south of the country [10].

In this study, the main aim is to study the effectiveness of using the Adaptive Neuro-Fuzzy Inference System (ANFIS) in rainfall and temperature predictions for the coming two decades in a region like Jordan which is classified as a semiarid and dry region. Weather elements data are multidimensional, non-linear, and dynamic. Therefore, to search for an appropriate model, a comparative evaluation is conducted to evaluate the proposed system against others found in the literature; the obtained results show the competiveness and the power of ANFIS technique for this study.

The remaining part of this study is structured as follow: the second section provides a definition for the ANFIS technique. The third section presents the research methodology followed in this study. The fourth section discusses the results. The final section concludes the study and suggests future work.

\section{ADAPTIVE NEURO FUZZY INFERENCE SYSTEM (ANFIS)}

The Adaptive Neuro-Fuzzy Inference System (ANFIS), which is the main interest of this study, was first introduced by 
Jang in 1993 [7]. ANFIS algorithm is the fuzzy-logic based paradigm that grasps the learning abilities of ANN to enhance the intelligent system's performance by using the knowledge gained after learning. Using a given input-output data set, ANFIS constructs a fuzzy inference system whose membership function parameters are tuned or adjusted using a hybrid type of neural algorithms [8]. Several techniques can be used for prediction such as neural network or fuzzy logic but ANFIS has largely extended the capabilities of both technologies in hybrid intelligent systems. The advantages of neural networks in learning and adaptation and those of fuzzy logic systems in dealing with the issues of human-like reasoning on the linguistic level, transparency and interpretability of the generated model as well as in handling uncertain or imprecise data, enable building higher level intelligent systems [14].

\section{ReSEARCh METHODOLOGY}

This study uses various combinations of data sets of Longterm rainfall readings from 26 stations in Jordan obtained from the Jordan Meteorological Department (JMD). These data represent annual historical rainfall readings for more than 30 years. Before starting the work, it is necessary to preprocess the data and remove outliers in order to compute average annual rainfall readings for the whole stations. GIS is a very useful tool which is used for computing and representing these data as shown in Fig. 1.

The fuzzy inference technique used in this study is the Mamdani method, which was proposed by Mamdani and Assilian. In Mamdani's model, the fuzzy implication is modeled by Mamdani's minimum operator. The conjunction operator is min, the t-norm from compositional rule is min, and for the aggregation of the rules, the max operator is used. The ANFIS Architecture used in this study is illustrated in Fig. 2. There are five layers in ANFIS which have one input layer with a neural training layer. The Fuzzification layer, which transfers the original crisp values into fuzzy ones, chooses the value with the maximum membership degree to participate in the process of the neural training layer according to the maximum membership degree principal. One output layer is similar to that in ANN but with a fuzzy number output.

Developing an index based on the fuzzy logic necessitates the comprehension of three important parts of the fuzzy inference system, including membership functions, fuzzy set operations and inference rules. Each selected input or input set has a domain called the universe of discourse that is divided into subsets which are expressed by linguistic terms. The relationships between the subsets of inputs and outputs, as well as those among the subsets of inputs, are defined by, if and then by rules and fuzzy set operators [6].

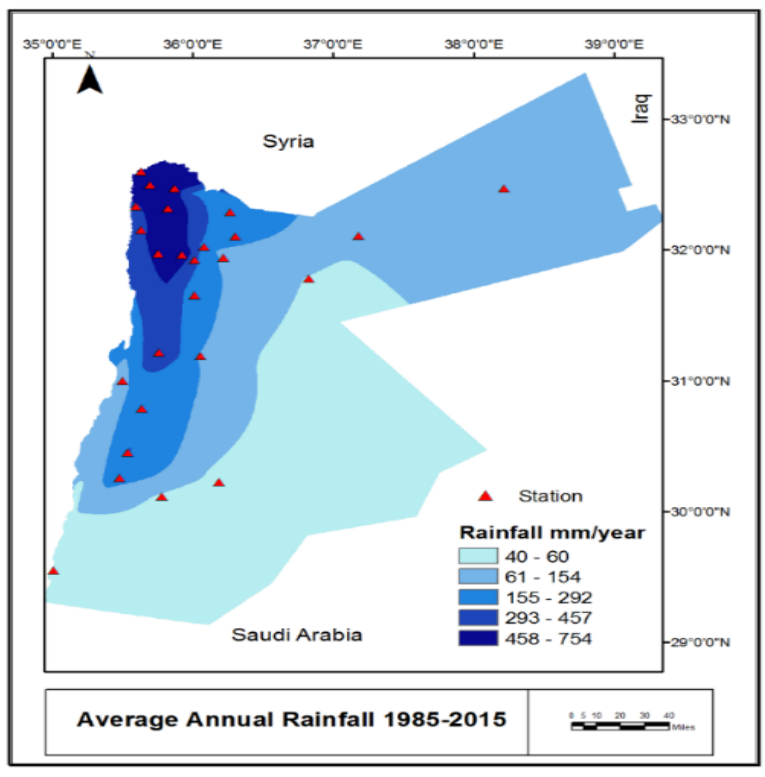

Fig. 1. Interpolated average annual rainfall for the period 1985-2015 of the study area.

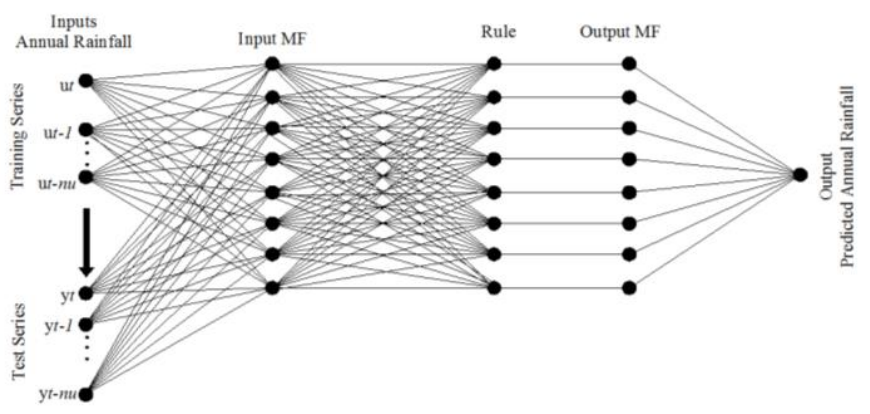

Fig. 2. General architecture of the used ANFIS.

In the Fuzzification of entries step, all variables are assigned to a membership function in order to be transformed from numerical to linguistic subsets such as small, poor, excellent or high ones. A Membership Function (MF) is a function that defines how each point in the input space is mapped to a membership value between 0 and 1 [15]. It is necessary to know that not only can a single map have more than one fuzzy membership function, but also several different maps can have membership values for the same proposition or hypothesis [2].

Defining the rules is an important step in the Fuzzy logic approach by which we link the hypothesis with the conclusion through a certainty factor. These rules are based on the form "if ...then and". The knowledge in a problem-solving area can be represented by a number of rules. The task of rules' definition is usually accomplished by experts with general knowledge on the specific field. There is no need for assigning weights in the criteria used.

The processing of the rules or inference step in Mamdani's approach consists of three stages [4]: 
a) Aggregation, which returns the fulfillment of hypothesis for every rule individually (max, sum).

b) Implication, which combines the aggregation's results to the rule's certainty factor (min, prod).

c) Accumulation, which brings together the individual results of the variables.

The Fuzzy gamma operation is used in this study, which is defined in terms of the fuzzy algebraic product and the Fuzzy algebraic sum by (1):

$$
\begin{gathered}
\mu(\mathrm{x})=(\text { Fuzzy Sum })^{\gamma} *(\text { Fuzzy Product })^{1-\gamma} \\
, 0 \leq \gamma \leq 1
\end{gathered}
$$

where $(\gamma)$ is a parameter chosen in the range $(0,1)$. The wise choice of the $(\gamma)$ produces output values that ensure a flexible compromise between the "increasing" tendencies of the Fuzzy algebraic sum and the "decreasing" effects of the Fuzzy algebraic product where $(\gamma)$ is a parameter chosen in the range $(0,1)$. When $(\gamma)$ is 1 , the combination is the same as the fuzzy algebraic sum; and when $(\gamma)$ is 0 , the combination equals the fuzzy algebraic product [9].

The defuzzification of the output fuzzied values is the transformation of the fuzzy set results into a linguistic expression or a crisp value [3]. This transformation can be done by several methods such as centroid, bisector, Middle, Smallest, and Largest of Maximum; the used method in this study is the Centroid defuzzification.

Centroid defuzzification returns the center of area under the curve; this method selects the output crispy value corresponding to the center of gravity of the output membership function. The only disadvantage of this method is that it is computationally difficult for complex membership functions [16].



Fig. 3. Flowchart of the methodology followed in conducting the study.
In this study, several membership functions were tested. The Gaussian shape membership function is used for representing the situation of rainfall in the study area. For the used Fuzzy Gamma operator, Bonham-Carter [2] discussed the effect of variations in $(\gamma)$ for the case of combining two values $\mu \mathrm{A}=0.75$ and $\mu \mathrm{B}=0.5$. In this study, several trials were performed to determine the value of gamma $(\gamma)$ which yields the best reliable rainfall map. $\gamma=0.85$ is the most satisfactory value for that.

The methodology followed in conducting this study is presented in Fig. 3. It show the processes in order, start with data processing using the GIS tool, after that the data will be processed using the simulator tool using the ANFIS.

\section{RESULTS}

In order to have the best results from the ANN models we change the number of the neurons, hidden layers and the learning and training algorithms which we did until reached the best results of the data. To study the effectiveness of ANFIS, three weather elements have been studied here, the rainfall, the maximum annual average temperature, and the minimum one. The following results were obtained for three elements simulated by ANFIS.

\section{A. ANFIS and Average Annual Rainfall Prediction}

The actual data for the annual average rainfall during the period 1985-2015 is shown in Fig. 1. As the figure illustrates, the output results for the study area have come up with five zones according to the average precipitation, which are: Very Poor, Poor, Moderate, High, and Very High. In this study, the results will be discussed and analyzed according to these classifications. Using the GIS tools, the area for each zone has been calculated from Fig. 1 .

The total area for the whole country is calculated by the same way using GIS tools, and then the percentage of each zone to the total country's area can be easily determined. Table I gives the calculated percentage of the actual data for the period from 1985-2015. ANFIS is introduced here to predict the average annual rainfall during the period 20162025 according to the method introduced before. The predicted results using ANFIS simulation are shown in Fig. 4.

Comparing between the predicted results in Table I and Fig. 1 and 4, it is clear that the area that has a very high rainfall zone intensity will witness a shrinkage to about $2.81 \%$ from $3.29 \%$ in comparison to the study area during the period 1985-2015. This means that the rainfall will be less in comparison to the actual data during the period 1985-2015.

The highest percentage portion of the study area, which is about $87.2 \%$, belongs to very poor rainfall intensity as shown in Table I. This means that the Country will witness a drawback in rainfall and more dryness as a lack of rainfall will be expected. These obtained results are in great consistency with previous studies which are related to rainfall predictions ([1], [11], [16], [17]). 
TABLE II. RAINFALL CLASSIFICATION RESULTS FOR BOTH ACTUAL AND SiMULATED DATA USING ANFIS

\begin{tabular}{|l|l|l|l|l|l|}
\hline Rainfall Class & $\begin{array}{l}\text { Very } \\
\text { High }\end{array}$ & High & Moderate & Poor & Very Poor \\
\hline $\begin{array}{l}\text { Area\% (1985- } \\
\text { 2015) Actual } \\
\text { data }\end{array}$ & 3.29 & 4.37 & 9.64 & 39.88 & 42.82 \\
\hline $\begin{array}{l}\text { Area\% (2016- } \\
\text { 2025) predicted } \\
\text { using ANFIS }\end{array}$ & 2.81 & 2.03 & 3.41 & 4.55 & 87.20 \\
\hline
\end{tabular}

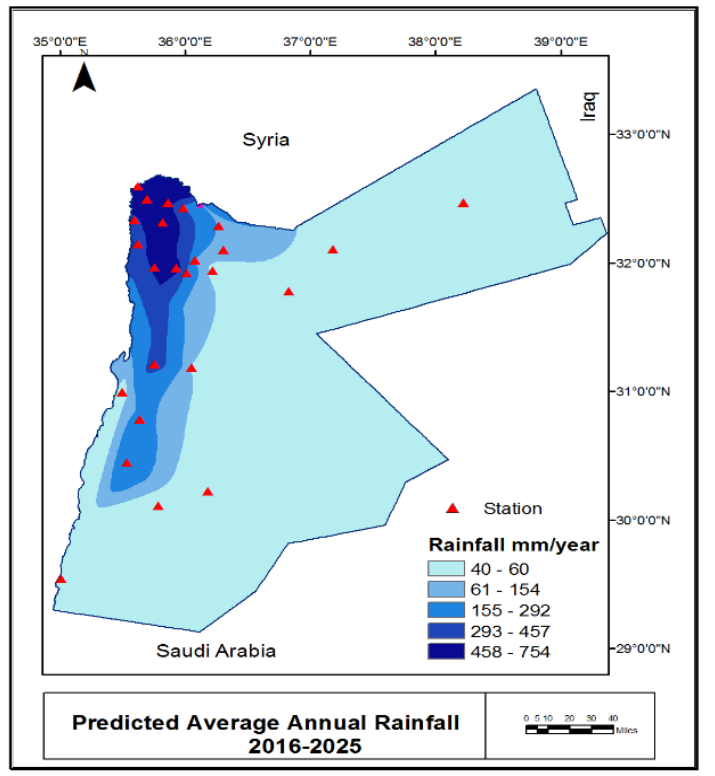

Fig. 4. Interpolated predicted average annual rainfall for the period 20162025 of the study area.

\section{B. ANFIS and Minimum Average Temperatures Prediction}

The total average annual minimum temperature for actual data during the period 1985-2015 and the predicted simulated data according to ANFIS during the period 2016-2025 are both shown in Fig. 6 after converting it to a map using GIS. Table II also shows the percentage of the actual data for the minimum temperature distributed all over the study area. The average minimum temperatures according to the actual data have also been classified into five zones, same as the rainfall pattern introduced before, and it is better to keep the same zones classification for rainfall pattern or comparison purposes. According to Fig. 5, the pattern zones for the average annual minimum temperature can be classified in ${ }^{\circ} \mathrm{C}$ as follows:

Very High: 14.9-19.8,

High: 13.1-14.8,

Moderate: 11.8-13.0,

Low: 10.2-11.7, and

Very Low: 9.0-10.1.

From Table II, it is clear that the ANFIS prediction shows that there is a change pattern in a minimum temperature at the country level, in comparison to the two periods 1985-2015 and 2016-2025. There is a clear decrease in the very high zone temperature for the period 2016-2025, which means that the potential for getting a colder weather among the area in the Rift valley -Middle West of the country- and north region in the country is possible. Since the calculated percentage of this area is very high it has decreased from $4.37 \%$ to $1.18 \%$ as indicated in Fig. 5 by red color zones. It is very interesting to see that the zone of low has tangibly shrink in a way that almost disappeared in the middle region zone in the country, and most of this zone has moved to the moderate zone which has been increased from $54.39 \%$ to $85.31 \%$ as illustrated in Table II. This will give an indication from this prediction that this middle region of the country will witness a higher pattern in its average annual minimum temperature compared to the period 1985-2015. This zone is indicated by the yellow color in Fig. 5.

TABLE III. AVERAgE ANNUAL Minimum TEMPERATURE RESUlts FOR Both ACTUAL AND SimULATED DATA USING ANFIS

\begin{tabular}{|l|l|l|l|l|l|}
\hline $\begin{array}{l}\text { Annual } \\
\text { Minimum } \\
\text { Temperature } \\
\text { ('C) }\end{array}$ & $\begin{array}{l}\text { Very } \\
\text { High } \\
\mathbf{1 4 . 9 -} \\
\mathbf{1 9 . 8}\end{array}$ & $\begin{array}{l}\text { High } \\
\mathbf{1 3 . 1 -} \\
\mathbf{1 4 . 8}\end{array}$ & $\begin{array}{l}\text { Moderate } \\
\mathbf{1 1 . 8 - 1 3 . 0}\end{array}$ & $\begin{array}{l}\text { Low } \\
\mathbf{1 0 . 2 -} \\
\mathbf{1 1 . 7}\end{array}$ & $\begin{array}{l}\text { Very } \\
\text { Low } \\
\mathbf{9 . 0 -} \\
\mathbf{1 0 . 1}\end{array}$ \\
\hline $\begin{array}{l}\text { Area\% (1985- } \\
\text { 2015) Actual } \\
\text { data }\end{array}$ & 4.37 & 7.67 & 54.39 & 30.4 & 3.17 \\
\hline $\begin{array}{l}\text { Area\% (2016- } \\
\text { 2025) predicted } \\
\text { using ANFIS }\end{array}$ & 1.18 & 8.21 & 85.31 & 4.73 & 0.57 \\
\hline
\end{tabular}

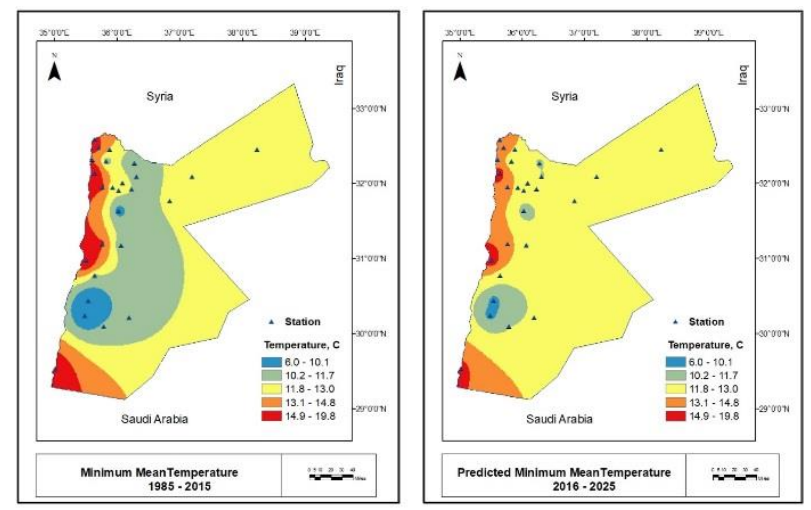

Fig. 5. Interpolated predicted average annual minimum temperature actual and predicted by using ANFIS.

\section{ANFIS and Maximum Average Temperatures Prediction}

The total average annual maximum temperature for the actual data during the period 1985-2015 and predicted simulated data according to ANFIS during the period 20162025 are both shown in Fig. 6 after using GIS tools. The classification of temperature zones based on the actual data plotted by GIS tools has come up with five zones same as rainfall and minimum temperature classification and will keep the same classification for the easiness of comparison as follows in $\left({ }^{\circ} \mathrm{C}\right)$ :

Very High: 29.0-31.4,

High: 26.0-28.9,

Moderate: 25.0-26.9,

Low: 23.0-24.9, and

Very Low: 19.0-22.9 
Table III gives a clear indication that the percentage changes in the average annual maximum temperature has not significantly changed in its patterns compared to the average annual minimum temperature shown in Table II. For example, the change in the moderate zones from period 1985-2015 to period 2016-2025 is only 5\% in difference when it is compared to the average annual minimum temperature in Table II. Moreover, there will be an increase in the southern region of the country for the Very High zone, which means that these areas, like the Gulf of Aqaba, will witness a temperature that is higher than the one witnessed in the previous period 1985-2015. This region is indicated in Fig. 6 with the red color. It is also clear that the low zone has clearly disappeared during the period 2016-2025, which means that this region will witness a higher temperature during the predicted period, and this is indicated in Fig. 6 with the dark green color. It is clear that the moderate zone has not changed significantly after the simulation and prediction. In other words, this region will not be affected by the weather changes in its pattern of the average annual maximum temperature. This region is indicated in Fig. 6 with the orange color and is almost known in Jordan as the desert area.

TABLE IV. AVERAge ANNUAL MAXIMUM TEMPERATURE RESUlTS FOR BOTH ACTUAL AND SIMULATED DATA USING ANFIS

\begin{tabular}{|l|l|l|l|l|l|}
\hline $\begin{array}{l}\text { Annual Maximum } \\
\text { Temperature }\left({ }^{\circ} \mathbf{C}\right)\end{array}$ & $\begin{array}{l}\text { Very } \\
\text { High } \\
\mathbf{2 9 . 0 - 3 1 . 4}\end{array}$ & $\begin{array}{l}\text { High } \\
\mathbf{2 6 . 0 -} \\
\mathbf{2 8 . 9}\end{array}$ & $\begin{array}{l}\text { Moderate } \\
\mathbf{2 5 . 0 - 2 6 . 9}\end{array}$ & $\begin{array}{l}\text { Low } \\
\mathbf{2 3 . 0 -} \\
\mathbf{2 4 . 9}\end{array}$ & $\begin{array}{l}\text { Very } \\
\text { Low } \\
\mathbf{1 9 . 0 -} \\
\mathbf{2 2 . 9}\end{array}$ \\
\hline $\begin{array}{l}\text { Area\% (1985- } \\
\text { 2015) Actual data }\end{array}$ & 4.16 & 61.01 & 13.9 & 15.6 & 5.33 \\
\hline $\begin{array}{l}\text { Area\% (2016- } \\
\mathbf{2 0 2 5}) \text { predicted } \\
\text { using ANFIS }\end{array}$ & 7.03 & 69.89 & 18.07 & 4.94 & 0.07 \\
\hline
\end{tabular}

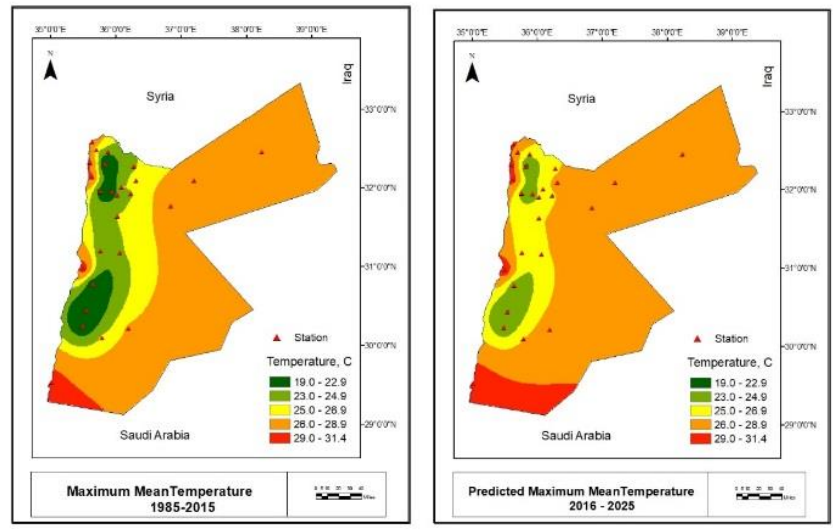

Fig. 6. Interpolated predicted average annual maximum temperature actual and predicted by using ANFIS.

\section{CONCLUSIONS AND FUTURE RESEARCH}

In this study it is clear that the model ANFIS has presented good results for simulating and predicting rainfall precipitation in the arid regions. The pattern according to the ANAFIS model has classified the study area into reasonable zones, which are consistent with the actual case study according to rainfall and temperature predictions. The predicted results have come up with a conclusion that there will be a decrease pattern in rainfall at the country level. For the temperature prediction results, the country will also witness a lower in minimum average annual temperature, and some regions have moved from lower region temperature zones to higher ones. The same behavior has been noticed on the average annual maximum temperature as some regions have a higher percentage area compared to the actual data during the period 1985-2015 which will mean a pattern changes in weather elements, while some regions has moved from the high zone to the moderate zone, which means a lower maximum temperature.

The initial investigation of applying the ANFIS technique to weather elements prediction shows a good performance, in the future, other artificial intelligence technique like NARXANN model can be used, also other factors of weather elements can be included like humidity, speed of the wind and height to show more valuable results.

\section{REFERENCES}

[1] A. Dahamsheh and H. Aksoy, Structural Characteristics of Annual Precipitation Data in Jordan, Theoretical and Applied Climatology, Vol. 88, No. 3-4,2007, pp. 201-212.

[2] B. Carter, F. Graeme, Geographic Information Systems for Geoscientists, Modelling with GIS, Oxford; Pergamon Press, 1994.

[3] C. Bezdek, Pattern Recognition with Fuzzy Objective Function Algorithms. New York: Plenum Press, 1981.

[4] E. Mandelas, T. Hatzichristos and P. Prastacos, A Fuzzy Cellular Automata Based Shell for Modeling Urban Growth - A Pilot Application in Mesogia Area .10th AGILE International Conference on Geographic Information Science, Aalborg University, Denmark,2007.

[5] G. Alfarisy and W. Mahmudy, Rainfall forecasting in Banyuwangi using adaptive neuro fuzzy inference system. Journal of Information Technology and Computer Science Vol.1, No. 1, 2016, pp. 65 - 71.

[6] H. Garibi, A. Mavi, R. Nabizadeh, H. Arabalibeik, M. Yunesian and M. Sowlat, A novel approach in water quality assessment based on fuzzy logic .Journal of Environmental Management, Vol. 112, 2012, pp.87-95.

[7] J. Jang, ANFIS: Adaptive-Network-Based Fuzzy Inference System. IEEE Trans. Syst. Man Cybern. Vol. 23, 1993, pp. 665-685.

[8] J. Patel and F. Parekh, Forecasting Rainfall Using Adaptive NeuroFuzzy Inference System (ANFIS). International Journal of Application or Innovation in Engineering \& Management (IJAIEM). Vol. 3, No. 6, 2014, pp 262- 269.

[9] J. Rather and Z. Raouf, Fuzzy Logic Based GIS Modeling for Identification of Groundwater Potential Zones in the Jhagrabaria Watershed of Allahabad District, Uttar Pradesh, India. International Journal of Advances in Remote Sensing and GIS, Vol.1, No.2, 2012.

[10] M. Freiwan and M. Kadioglu, Spatial and temporal analysis of climatological data in Jordan. International Journal of Climatology, Vol 28, No. 4, 2008, pp.521-535.

[11] M. Matouq, T. El-Hasan, H. Al-ilbisi, M. Abdelhadi, M. Hindiyeh, S. Eslamian and S. Duheisat, The climate change implication on Jordan: A case study using GIS and Artificial Neural Networks for weather forecasting, Journal of Taibah University for Science, Vol. 7, No. 2, 2013, pp. 44-55

[12] M.L. Parry, O.F. Canziani, J.P. Palutikof, P.J. van der Linden and C.E. Hanson, IPCC, Climate Change 2007: Impacts, Adaptation and Vulnerability. Contribution of Working Group II to the Fourth Assessment Report of the Intergovernmental Panel on Climate Change, Cambridge University Press, 2007.

[13] N. Bushara and A. Abraham, Computational Intelligence in Weather Forecasting: A Review. Journal of Network and Innovative Computing, Vol. 1, No. 1,2013, pp. 320-331.

[14] N. Bushara and A. Abraham, Using Adaptive Neuro-Fuzzy Inference System (ANFIS) to Improve the Long-term Rainfall Forecasting. Journal of Network and Innovative Computing,Vol. 3, No.1,2015, pp. 146-158. 
[15] P. Riad, M. Billib, A. Hassan and M. Omar, Overlay Weighted Model and Fuzzy Logic to Determine the Best Locations for Artificial Recharge of Groundwater in a Semi-Arid Area in Egypt, Nile Basin .Water Science \& Engineering Journal, Vol. 4, No.1, 2011.

[16] S. Naaz, A. Alam, and R. Biswas, Effect of different defuzzification methods in a fuzzy based load balancing application. International
Journal of Computer Science Issues, Vol.8, No. 5, 2011.

[17] T. Alwada'n, B. Zahran, A. Mesleh, M. Matouq and O. Al-Heyasat, Rainfall Prediction in Semi-Arid Regions in Jordan Using Back Propagation Neural Networks International Journal on Engineering Applications, Vol. 3, No. 6, 2015 pp.158-163. 